\title{
An early hominin arrival in Asia
}

An excavation has uncovered stone tools in China that are about 2.1 million years old. This evidence pushes back the date of the earliest established signs of a hominin species outside Africa. SEE LETTER P.608

\section{JOHN KAPPELMAN}

$\mathrm{I}$ magine a world nearly devoid of humans. This theme is often explored in postapocalyptic science fiction, and it was the case for most of Earth's history until early hominins (members of the evolutionary tree that includes humans, extinct species of the genus Homo and other closely related bipedal species) moved out of Africa into unknown territories, to eventually populate the planet. Which hominins made this journey? When and how did they migrate, and by which routes? Field-based research that uncovers traces of these early dispersals could provide some answers, as well as insight into hominin behaviour. On page 608, Zhu et al. ${ }^{1}$ report evidence of hominin activity in China more than 2 million years ago, revealing an earlier time frame than was previously known for a hominin presence outside Africa.

Establishing the first known occurrence of a species requires incontrovertible evidence to confirm the presence of the species and firm support for the age of the geological material that contains such a sample. The remains of species that were common where they lived are usually found with ease in fossil deposits. By contrast, populations of ancient hominins were probably rare, and their fossilized remains are generally scarce. Just a single finger bone can suffice to document a hominin presence ${ }^{2}$. However, when hominins began to fashion tools from stones, at least 3.3 million years ago ${ }^{3}$, the purposely chipped cobbles and flakes that they produced became another calling card that can attest to a hominin presence.

Until now, the oldest known hominin site outside Africa ${ }^{4}$ was in Dmanisi, Georgia. Excavations at that site uncovered spectacular finds of the roughly 1.85 million- to 1.78 -millionyear-old remains of multiple hominins and stone tools. Numerous later sites of hominin activity, at locations stretching from western Europe $^{5}$ to eastern Asia $^{6}$, have also been investigated thoroughly. Zhu and colleagues' report of signs of a hominin presence at Shangchen in China's Loess Plateau (Fig. 1) is based on evidence from only stone tools, and the researchers found that these tools were distributed in layers of sediment that date back to about 2.1 million years ago.

The age of many hominin sites has been

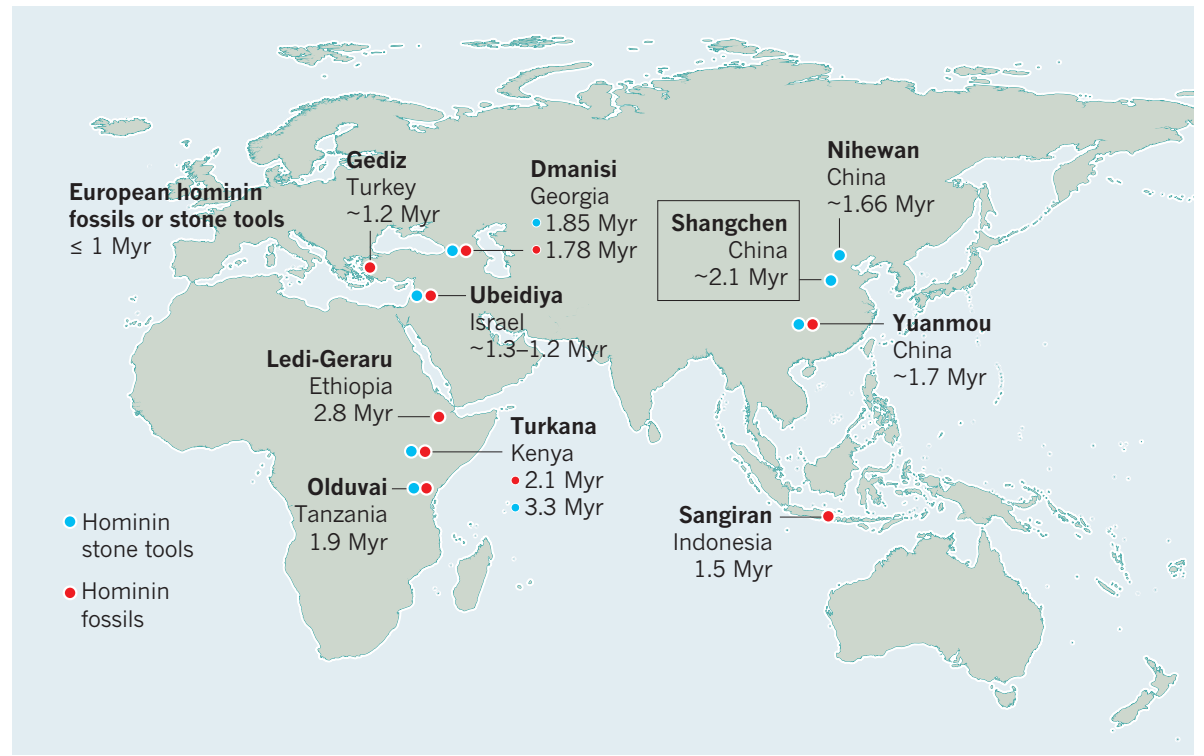

Figure 1 | Ancient sites of hominin presence. Zhu et al. ${ }^{1}$ report their discovery of approximately 2.1-million-year-old stone tools at Shangchen in China's Loess Plateau, which provides the earliest known evidence for the presence of hominins (the evolutionary group that includes humans, extinct species of the genus Homo and related bipedal species) outside Africa. The dates (Myr, million years ago) and locations of some of the important earliest known sites of hominin fossils and stone tools are shown.

estimated by methods such as radiometric dating, or by the chemical fingerprinting of volcanic rocks. Because Shangchen lacks volcanic rocks, Zhu and colleagues instead used palaeomagnetic dating to analyse sediment layers called palaeosols (fossilized soils) and loess (wind-blown silts). This technique relies on the fact that Earth's magnetic field undergoes random reversals ${ }^{7}$, in which the magnetic north pole becomes the magnetic south, and vice versa. Magnetic minerals in sediments act like small compasses that register the polarity, and when such sediments become rock, the polarity of that time is locked in. The pattern of polarity reversals in these ancient sediment layers provides a fingerprint that can be matched to a dated reference called the geomagnetic polarity timescale (GPTS) . $^{8}$

The site at Shangchen contains steep, deeply incised outcrops that include slopes covered in vegetation, which makes sample collection a literal cliffhanger. The authors' data provide a convincing correlation to the GPTS, and the team was able to identify two notable events from the GPTS (the brief Réunion Subchron ${ }^{9}$ and the later, but slightly longer, Olduvai
Subchron), which bookend the layer that contains the oldest artefacts. Can we be certain that the researchers found the oldest tools at the site? The team's ability to reach the deeper layers was limited because of the present active farming of the fields. Investigating such layers should be a goal of future work.

The 96 excavated stone tools that Zhu et al. analysed were mainly small stone flakes and cobbles, which contrasted sharply with the fine-grained material that surrounded the artefacts. The authors propose that hominins transported these rocks from the Qinling Mountains to the south. If the exact source of the stones could be determined, it would provide important information about how far these hominins transported raw materials.

The stone tools are simple in form: the palm-sized rock cores had a limited number of flakes removed, with some of the flakes showing an apparent subsequent resharpening, and several cobbles might have been used as hammerstones. These characteristics closely align the Shangchen tools with those of a similar age found in Africa ${ }^{10}$. The authors do not report any matching refit of flakes to 
each other or to the cores from which they were chipped, so flake production might have occurred elsewhere. However, because the steepness of the slopes at the site rarely permitted the team to open large excavations, this prospect remains to be examined thoroughly.

What were the stone tools used for? Zhu et al. note the discovery of animal remains near the oldest tools, including bones belonging to bovids (a family that includes antelopes and cattle), cervids (comprises deer) and suids (pigs). The authors did not address whether this association provides evidence of tool use for carcass processing. To evaluate the possibility, it would be necessary to identify signs such as: cut marks on the bones that point to flesh removal with tools; breakage marks on the bones, suggesting that they had been hammered to extract bone marrow; tool wear; or the presence of trace biological residues on the tools. If this question is investigated in the future, the degree of post-recovery cleaning of the stone tools might have compromised the use of approaches ${ }^{11}$ such as residue studies.

Hominins originated in Africa possibly more than 6 million years ago ${ }^{12}$. The absence in Eurasia of both any hominin sites dating to the early portion of this interval and any fossils that can be attributed to hominin genera such as Australopithecus and Paranthropus, found in Africa until about 1 million years ago, points instead to a species of Homo as the most likely candidate for the first hominin to have left Africa. The oldest known African fossil attributed to Homo is a 2.8-million-year-old jawbone from Ethiopia ${ }^{13}$, which provides a time estimate for the earliest possible exit of the genus from Africa. Of course, the actual date of departure might have been later.

The hominin dispersal probably occurred under the variable climates of the Pleistocene ice age. Does a migration to higher latitudes suggest the evolution of behavioural adaptations to colder climates? Perhaps. The conventional interpretation that the palaeosols of the Loess Plateau formed during favourable warm and wet conditions, and its loess under harsher cold and dry conditions, is probably an oversimplification $^{14}$, but at the Shangchen site, palaeosol layers containing stone tools outnumber loess layers containing such tools by a ratio of about $2: 1$. Rather than maintaining a continuous occupation of the Loess Plateau, the hominin population might have increased or dwindled, depending on the climate ${ }^{15}$.

The roughly 14,000-kilometre trek from eastern Africa to eastern Asia represents a range expansion of dramatic proportions. The dispersal of hominins was probably facilitated by population increases as they moved into new territories and filled empty niches, and could also have been driven by the phenomenon of resource depletion that underlies the high mobility of today's hunter-gatherers ${ }^{16}$. Yet even with a dispersal rate of only 5-15 kilometres per year, a value well inside the daily foraging range of modern hunter-gatherers ${ }^{17}$, the distance between Africa and Asia could have been covered in just 1,000-3,000 years. The present record of hominin sites and the dating techniques that are currently available to researchers are not sufficient to resolve a dispersal event of such potential speed, or to determine its exact form, but we can surely look forward to more finds that will help to solve this migration mystery.

John Kappelman is in the Departments of Anthropology and Geological Sciences, The University of Texas at Austin, Austin, Texas 78712, USA.

e-mail:jkappelman@austin.utexas.edu

1. Zhu, Z. et al. Nature 559, 608-612 (2018).

2. Groucutt, H. S. et-al. Nature Ecol. Evol. 2, 800-809 (2018)

3. Harmand, S. et al. Nature 521, 310-315 (2015)

4. Ferring, R. et al. Proc. Natl Acad. Sci. USA 108, 10432-10436 (2011).
5. Muttoni, G., Scardia, G. \& Kent, D. V. Quat. Sci. Rev. 180, 1-29 (2018).

6. Zhu, R. X. et al. Nature 431, 559-562 (2004).

7. Phillips, J. D. \& Cox, A. Geophys. J. Int. 45, 19-33 (1976).

8. Ogg, J. G. in The Geologic Time Scale 2012 (eds Gradstein, F. M., Ogg, J. G., Schmitz, M. D. \& Ogg, G. M.) 85-114 (Elsevier, 2012).

9. Quidelleur, X., Holt, J. W., Salvany, T. \& Bouquerel, H. Geophys. J. Int. 182, 699-710 (2010)

10. Shea, J. J. in Out of Africa I (eds Fleagle, J. G., Shea, J. J., Grine, F. E., Baden, A. L. \& Leakey, R. E.) 47-64 (Springer, 2010).

11.Nowell, A. et al. J. Archaeol. Sci. 73, 36-44 (2016),

12. Klein, R. G. The Human Career 3rd edn (Univ. Chicago Press, 2009).

13. Villmoare, B. et al. Science 347, 1352-1355 (2015)

14. Stevens, T. et al. Nature Commun. 9, 983 (2018).

15.Prat, S. C. R. Palevol 17, 6-16 (2018).

16.Venkataraman, V. V., Kraft, T. S., Dominy, N. J. \& Endicott, K. M. Proc. Natl Acad. Sci. USA 114, 3097-3102 (2017)

17. Kelly, R. L. The Lifeways of Hunter-Gatherers (Cambridge Univ. Press, 2013).

This article was published online on 11 July 2018.

\title{
QUANTUM PHYSICS
}

\section{Quantum optics without photons}

\begin{abstract}
Atoms can exhibit wave-like behaviour to form matter waves. Such waves have been used to model the basic processes that underpin how light interacts with matter, providing an experimental platform for future research. SEE LETTER P.589
\end{abstract}

\section{ALEJANDRO GONZÁLEZ TUDELA \& J. IGNACIO CIRAC}

7 The fundamental theory that describes the interaction between light and matter at microscopic scales is known as quantum optics. One of the most striking and tangible consequences of this theory is that excited atoms in the quantum electrodynamic vacuum - a state that contains no photons, often referred to simply as the vacuum - can decay to their ground state by emitting a photon, a process called spontaneous emission. In 1946, physicist Edward Mills Purcell proposed that this process can be tailored by structures that alter the photonic environment ${ }^{1}$, such as photonic crystals ${ }^{2}$, engineered dielectrics (insulators) in which light cannot propagate at certain frequency ranges. In the 1990 s, it was predicted ${ }^{3}$ that spontaneous emission in photonic crystals leads to exotic decays, in which photons

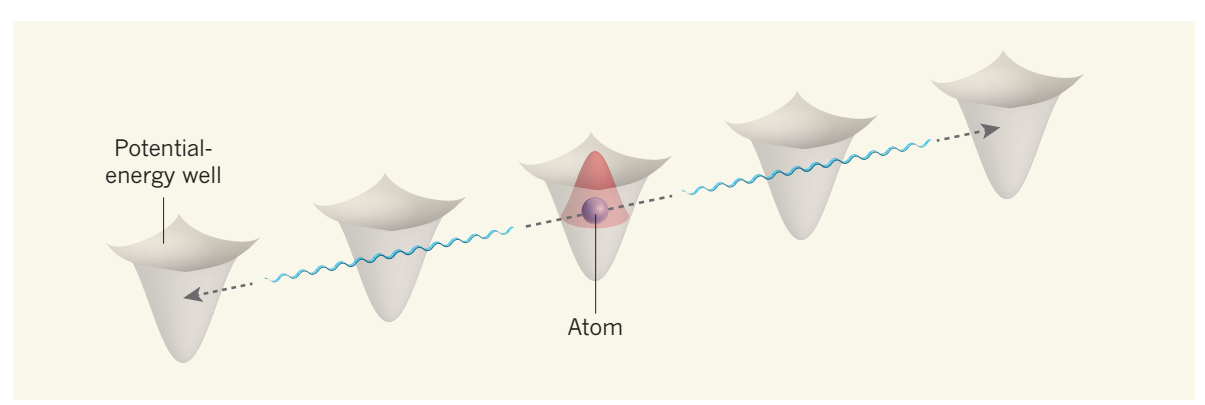

Figure 1 | Matter-wave emitters. Krinner et $a l^{4}$ trapped rubidium atoms in a one-dimensional optical lattice formed by the interference of laser fields - the interference generates a periodic pattern of light intensity that corresponds to a series of potential-energy wells, in which atoms can be confined. Each atom has two internal states, one of which (red) is confined to the atom and the other (blue) which is unconfined and overlaps with adjacent empty wells. By tuning the parameters of the system, the authors could make occupied lattice sites emit atoms as waves (dotted arrows) that travel along the lattice. The emission mimics that of photons from atoms confined in photonic crystals (materials engineered so that light cannot propagate at certain frequency ranges). 